\title{
Impact of Rhinovirus Infections in Children
}

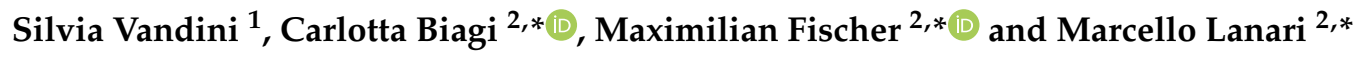 \\ 1 Pediatric Unit, Imola Hospital, 40026 Imola, Italy; s.vandini@ausl.imola.bo.it \\ 2 Pediatric Emergency Unit, Department of Medical and Surgical Sciences (DIMEC), \\ St. Orsola-Malpighi Hospital, University of Bologna, 40138 Bologna, Italy \\ * Correspondence: carlotta.biagi2@unibo.it (C.B.); maximilian.fischer9011@gmail.com (M.F.); \\ marcello.lanari@unibo.it (M.L.)
}

Received: 29 March 2019; Accepted: 4 June 2019; Published: 5 June 2019

check for updates

\begin{abstract}
Rhinovirus (RV) is an RNA virus that causes more than $50 \%$ of upper respiratory tract infections in humans worldwide. Together with Respiratory Syncytial Virus, RV is one of the leading causes of viral bronchiolitis in infants and the most common virus associated with wheezing in children aged between one and two years. Because of its tremendous genetic diversity ( $>150$ serotypes), the recurrence of RV infections each year is quite typical. Furthermore, because of its broad clinical spectrum, the clinical variability as well as the pathogenesis of RV infection are nowadays the subjects of an in-depth examination and have been the subject of several studies in the literature. In fact, the virus is responsible for direct cell cytotoxicity in only a small way, and it is now clearer than ever that it may act indirectly by triggering the release of active mediators by structural and inflammatory airway cells, causing the onset and/or the acute exacerbation of asthmatic events in predisposed children. In the present review, we aim to summarize the RV infection's epidemiology, pathogenetic hypotheses, and available treatment options as well as its correlation with respiratory morbidity and mortality in the pediatric population.
\end{abstract}

Keywords: Rhinovirus; bronchiolitis; asthma; wheezing; immune response

\section{Introduction}

Rhinovirus (RV) has long been known to be the main etiologic agent of "common colds", which are clinically characterized by an association of such signs and symptoms as rhinorrhea, nasal congestion, sore throat, cough, headache, and diffuse malaise. Overall, it is a relatively frequent but otherwise mild, self-limited syndrome. Therefore, its importance as possible causal factor of severe illness has often been neglected [1]. Nevertheless, in the last few decades, the impact of RV infection on the subsequent development of wheezing and asthma has been the subject of several studies. The following sections highlight the most recent discoveries concerning RV biochemical features as well as the related infection's pathogenesis, the activation of host immunological response, the actual available therapeutic strategies, and RV's correlation with respiratory morbidity in childhood.

\section{Epidemiology}

RV circulates worldwide. Infected healthy infants and adolescents are sometimes asymptomatic or may manifest mild signs and symptoms. Nevertheless, RV has been recognized as one of the most common respiratory viruses detected among patients affected by many infections, such as otitis media, croup, bronchiolitis, and pneumonia, and exacerbations of underlying chronic lung diseases [2-6]. In the world's temperate climate zones, the peak incidence of RV infection usually occurs in the period from early fall to the middle to end of spring [7].

Most RV infections are acquired in the community. However, more and more nosocomial and/or health-associated outbreaks have recently been reported, and have affected both patients and sanitary 
staff members [8]. RV transmission generally occurs through direct exposure to, and inhalation of, respiratory droplets/micro-droplets, even though it can also take place via fomites (contaminated surfaces), including direct person-to-person contact, since RV has moderate resistance to alcohol hand rubs and to other common disinfectants [9]. The growing use of multiplex diagnostic platforms has allowed for us to have deeper insight into the causal relationship between respiratory diseases and $\mathrm{RV}$, which has been commonly identified as "additional/co-pathogen" by recent epidemiologic data, especially in young children with acute Respiratory Tract Infection (RTI) [10]. A rising number of studies [11-14] report RV involvement to be the main or a significant etiologic agent in more than $50 \%$ of upper respiratory tract infections (URTIs), as well as to have a potential role as a trigger of asthmatic flares in both adults and children, highlighting the fact that this viral pathogen causes greater morbidity than previously recognized. RV is acknowledged to be the second most frequent cause of viral bronchiolitis, after Respiratory Syncytial virus (RSV), and it is probably deeply involved in the development of wheezing during the first years of life, as reported in several studies [15-20]. To date, approximately $20-40 \%$ of infants under one year of age that have been diagnosed with bronchiolitis seem to be infected or co-infected by $\mathrm{RV}$, a rate that rises up to about $50 \%$ when considering hospitalized infants under three years of age [21].

A recent European study conducted on paediatric cases (persons under 14 years of age) of Community-Acquired Pneumonia (CAP), as confirmed by a Chest X-ray, reported the isolation of $\mathrm{RV}$ in $29 \%$ of the examined population, with $40 \%$ of them as a concurrent agent of two or more virus species [10]. Multiple viral infection was reported as the most prevalent etiology in toddlers, while clinical severity was not apparently increased in this age group. A nested study in the context of the broader and well-known Etiology of Pneumonia in the Community Study (EPIC) analyzed the 13 most commonly isolated respiratory viruses and noted a $24.4 \%$ isolation rate for one or more viruses from asymptomatic children [22]. At the same time, literature data show that the RV wheezing illness represents a strong predictor of subsequent wheezing/asthma, especially in two types of high-risk cohorts: early wheezers with an atopic background and/or pediatric patients hospitalized for early onset wheezing consequences [23-26]. Nevertheless, the real role of RV in otherwise healthy infants lacking an a priori increased risk of asthma is still unknown. One study, conducted by De Winter et al. [27] on a low-risk cohort (no family history of asthma, no prior hospitalization for infant respiratory/wheezing illness), suggested that RV-induced wheezing in early life might be a risk factor for subsequent development of wheezing/asthma in high-risk, but also in low-risk, populations of children. The results of these studies demonstrated that RV causes less structural damage in the airways than RSV, but it may determine bronchial hyper-reactiveness in predisposed patients; in both cases, the interactions among the viral load, pathogenicity, and the genetic features of the host (i.e., family history of allergy and atopy and environmental factors, including airway microbiome and exposure to tobacco smoke or pollution) influence the onset and severity of subsequent wheezing and asthma disease [23-27]. High-risk birth cohort studies report that RV-induced bronchiolitis and wheezing are a strong risk factor for school-aged asthmatic illness $[17,25,28,29]$. These results were confirmed by a multicenter cohort study [30] analyzing 921 infants under one year of age: three different profiles of severe bronchiolitis were identified. Bronchiolitis RSV-negative (mostly due to RV) was related to a history of breathing disorder and/or eczema during infancy as well as to a higher blood eosinophils count.

\section{Microbiological and Immunological Aspects}

From a microbiological point of view, RV is currently included in the Picornaviridae family. Before the molecular era, RV was considered to be different from enteroviruses, since, unlike them, it is inactivated by acid. The actual availability of modern molecular techniques contributed to clarifying the genetic similarity between RV and enteroviruses and also between the various RV species. For example, RV 87 and enterovirus D68 are very similar from a genetic point of view and both are acid-sensitive.

According to the latest ICTV release [31], we recognize three main RV species (RV-A, RV-B, and $\mathrm{RV}-\mathrm{C}$ ) under the genus Enterovirus, including also Enterovirus A e H and Enterovirus J. Furthermore, 
these specific species of RV account for more than 150 distinct serotypes [32]. RV is a non-enveloped, spherical virus with a mean diameter of about $30 \mathrm{~nm}$. The viral capsid is composed of the four capsid proteins VP1, VP2, VP3, and VP4. The first three are present on the cell surface, while VP4 is found below the capsid. The icosahedral capsid contains a 7.2-kb positive-sense single-stranded RNA viral genome; several nonstructural proteins, such as $2 \mathrm{~A}, 2 \mathrm{~B}, 2 \mathrm{C}, 3 \mathrm{~A}, 3 \mathrm{~B}, 3 \mathrm{C}$, and $3 \mathrm{D}$, have been identified [33]. The genomic structure of RV is reported in Figure 1. The transmission of viral particles between humans is caused by direct contact or through the fomites [34]. RV survives on hands and surfaces for several hours, so human-to-human transmission is relatively frequent, particularly in the presence of high viral loads [35]. The airway epithelium is the primary site infected by RV; most RV-A and -B serotypes use Intercellular Adhesion Molecule (ICAM)-1 to enter inside the cell or may alternatively bind Low Density Lipoprotein Receptor (LDL-R), whereas RV-C generally acts by infecting the cells through a different receptor molecule section. A recent study [36] found no significant differences in the cytokine levels (IFN- $\gamma$, IL-4, IL-10, TGF- $\beta$ ) in a nasal sample during RV-A, $\mathrm{B}$, or $\mathrm{C}$ infections. The mechanisms of response of the airway to $\mathrm{RV}$ infection have been extensively investigated because of their crucial rule in the complex and multifactorial process of development of asthma and recurrent wheezing at later ages. Unlike other respiratory viruses (i.e., RSV and Influenza Virus), RV alone does not cause direct airway epithelial cell destruction and does not have a definite cytopathic effect [37]. Instead, RV compromises the epithelial barrier's function by dissociation of the zonula occludens- 1 of the cells from the tight junction complex through the release of reactive oxygen species during viral replication [38]. In addition, the immune and adaptive immune response contributes to the pathogenesis of the infection through the activation of MDA1 and RIG1 genes and the synthesis and early secretion of IFNs and other pro-inflammatory cytokines (RANTES, IP-10, IL-6, IL-8, and ENA-78 [39]). Type I IFNs modulate the infection process through several infection control mechanisms [40], including the blocking of viral entry into cells, control of viral transcription, cleavage of RNA, inhibition of translation, and induction of apoptosis [41]. Moreover, IFNs indirectly mediate the production of cytokines and chemokines and the subsequent recruitment of natural killer cells and CD4 and CD8 T cells [42], the upregulation of the expression of major HLA I on cells, and upregulation of antigen-presenting cell mediators. Furthermore, RV infection also determines serotype-specific IgG neutralizing serum antibodies and IgA secretory antibodies in the airways, which are usually detectable one or two weeks after inoculation and maintain traceable levels for at least one year [39]. This humoral response seems to be serotype-specific, with only a minor fraction of antibody cross-reacting; for this reason, vaccine development is still very difficult. As reported in the literature, infected subjects with asthma show an increased number of lymphocytes and neutrophils in respiratory secretions and bronchial biopsy specimens whereas control subjects (without asthma) more often exhibit more lymphopenia associated with T cell infiltration of the airway's epithelium and submucosa [43]. The findings of previous studies led some authors to hypothesize that immune responses against RV in the asthmatic patient may result in an inappropriate (delayed and/or deficient) process, with subsequent increased severity of post-infectious wheezing [44].

Several studies confirmed the role of interferons in susceptibility to asthma exacerbations in pediatric populations. A study by Miller et al. [45] analysed the role of upper viral infections in asthma exacerbations, demonstrating that RV was related to asthma exacerbation and was mainly mediated by an increased type III IFN response.

These results are similar to those reported in another study [46] that demonstrated that an increased susceptibility to severe respiratory viral infection during the first years of life is partly related to the development of dysfunctionality of key mechanisms that mediate innate immune defense, which manifests primarily as markedly consistent higher type III IFN responses. Another very recent study (Khoo et al., 2019 [47]) identified a new immunological phenotype related to different up- and downregulation of cytokines and different IFN types, with different susceptibility to asthma exacerbations. 
A recent study conducted by Turi et al. [48] identified two different clusters of immune response to RSV and RV. One cluster, in common for both viruses, was characterized by increased type- 2 and type-17 immune mediator (IL-4, IL-5, IL-13, IL-17, IL-20, IL-23, IL-33, and TSLP, a key regulator of asthma development) release, and it was linked to a higher risk of recurrent wheezing. In contrast, epithelial growth factor (EGF) appeared to be inversely related to the risk of subsequent development of respiratory morbidity, since it plays a key role in the tissue-repairing process. Moreover, advanced molecular diagnosis techniques are available to confirm these mechanisms, and they have been used to demonstrate that RV-A and RV-C are more often related to the onset of recurrent wheezing [49]. Another recent study, produced by Fedele et al., confirmed that a Th2-mediated immune response is more frequent after RV infection than after RSV infection, and this may explain the higher incidence of subsequent wheezing and asthma development after RV bronchiolitis [50].

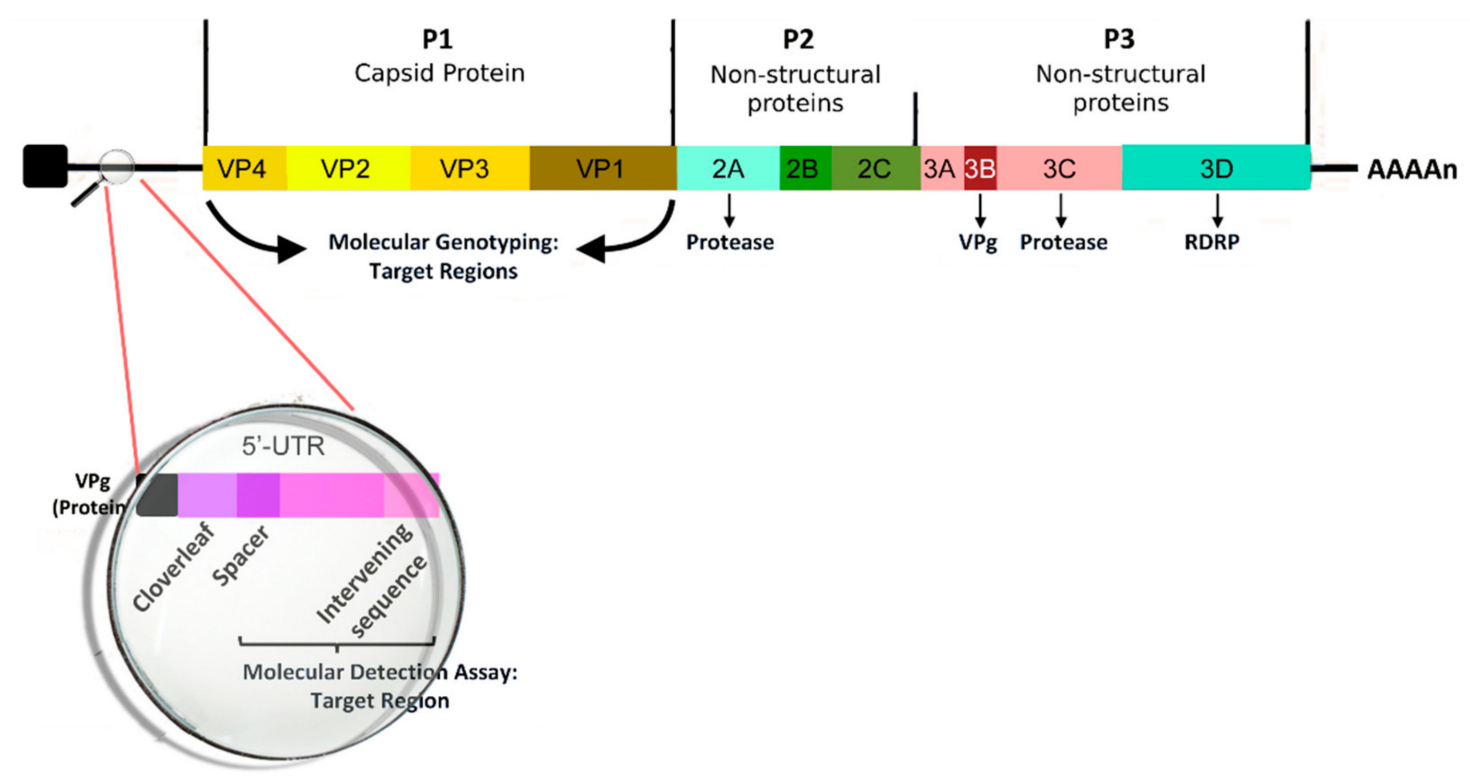

Figure 1. The genomic structure of Human Rhinovirus.

Correlations between allergic sensitization and RV-induced wheezing are receiving more attention, and aim to clarify how a pre-existing risk for allergy and atopic disease affects the human immune response to RV infection and, at the same time, conversely how RV infection modifies the airway structure and organisms' inflammatory state, increasing the risk of bronchial hyper-reactivity and wheezing [17]. For example, some studies have demonstrated that both RV infection and direct exposure to allergens cause, in the airways, epithelial cell production of IL-25 and IL-33, which are mediators involved in the type 2 airway inflammation and remodeling process [51,52]. Furthermore, the IL-33 polymorphism is significantly associated with the risk of the induction of intermediate and late-onset wheezing and allergic sensitization. However, it is still controversial whether genetic factors affect the immune response and subsequent airway reactivity and inflammation. The first barrier against RV infection is the airway epithelium, which is relatively resistant to infection when undamaged. In contrast, a disrupted airway epithelium may favor viral entrance in deeper cell layers, where RV has been demonstrated to replicate more actively. A damaged airway epithelium can also allow for the absorption of a higher amount of aeroallergens [53]. Moreover, RV can contribute to the airway remodeling process's activation and maintenance by upregulating molecules, such as Vascular Endothelial Growth Factor (VEGF), TGF- $\beta$, and any type of chemoattractant for airway smooth muscle cells. This process may be more intense in young infants [54-56]. As recently described in a paper by Shariff et al. [54], recurrent RV infections are a strong stimulus for airway remodeling through an increase in smooth muscle cell mass recruitment next to the epithelial cells mediated by chemotactic molecules, such as CCL5, CXCL8, and CXCL10, which are secreted during RV infections. The mechanism of airway remodeling 
that is induced by RV was also described in a study by Leigh et al. [55]: RV infection determines the upregulation of such molecules as amphiregulin, activin A, and VEGF, which are notoriously involved in the remodeling of bronchial epithelial cells. Moreover, a recent study run on animal neonatal models by Hong et al. demonstrated that RV infection acquired in early life stages in mice induced an IL-13- and IL-25-mediated Th2 immune response with parallel suppression of IFN- $\gamma$, IL-12, and tumor necrosis factor (TNF)- $\alpha$ [56]. These modifications were shown to play a crucial role in asthma development, with detrimental changes in airway homeostasis, consisting of innate lymphoid cell expansion, mucous hypersecretion, and airway responsiveness; these findings were detected especially when RV infection occurred in the first months of life. Indeed, early infections occurring during the neonatal period may trigger a Th2 immune response, with a negative impact on lung development, thereby exposing the patient to a significant risk of chronic respiratory disease [57]. Moreover, the literature reports that the developing immune system is not able to activate an efficient "adult-type" immune response. This mechanism is due to the need, during the first months of life, to maintain the preservation of the delicate balance between the onset of potentially damaging, pro-inflammatory Th1 responses and the less damaging Th2- and Treg-mediated responses. As recently discussed by Kollman et al. [58], the immunologic function in the neonatal period is the result of a complex interaction among autonomous cell immunity, nutrition immunity, antigen-specific immunity, and leukocyte immunity.

Moreover, a recent birth cohort study [59] reported that the risk of severe lower RTI and subsequent development of wheezing during early infancy is directly related to a low production of type I and III IFN by cord blood mononuclear cells in response to viral infections.

Th1 cells produce interferon-gamma, IL-2, and TNF-beta, which activate macrophages and are responsible for cell-mediated immunity and phagocyte-dependent protective responses. In contrast, Th2 cells produce IL-4, IL-5, IL-10, and IL-13, which are responsible for triggering strong antibody production, eosinophil activation, and the inhibition of several macrophage functions, thus providing phagocyte-independent protective responses. Studies conducted on animal models $[60,61]$ show that IL-13 is strongly induced during RV infections in neonatal mice, but not in adult mice. Moreover, in the Th2 immune response an increased production of IL-4, IL-33, and IL-25 [53,57] was observed. Increased Th2 responses are clearly involved in the onset of asthma and other atopic conditions because IL- 4 and IL-13 are required for IgE synthesis and IL- 5 is necessary for the recruitment of eosinophils. Another very recent study [62], enrolling 1016 infants $<12$ months in 17 U.S. centers, confirms that high levels of cytokines inducing a Th2 immune response (IL-4, IL-5, IL-13, and Thymic Stromal Linphopoyetin) are significantly related to the onset of asthma in infants up to four years of age. The main mechanisms that may explain the inflammatory response's intensification during $\mathrm{RV}$ infection could be the impairment of the primary airway barrier's function through a physical injury [63]. Furthermore, a prospective study, run on a cohort of nearly 5000 infants in Argentina, demonstrated that IL-13 may play an important role in the incidence of life-threatening RV infection, while levels of IFN- $\gamma$, viral load, and RV group were not significantly associated with the severity of the disease [64]. Some studies used the human challenge model to investigate the mechanism of viral infection, the response to RV infection in asthmatic hosts, and the worsening of virus-induced asthma activity [65] with the aim of developing new therapeutic strategies to control virus-induced inflammation and prevent the exacerbation of already-characterized asthmatic and wheezing episodes. RV-A and RV-C are more often related to wheezing in asthma exacerbations than RV-B, considering young subjects; RV-C, on the other hand, was associated with a more severe exacerbation and a higher hospitalization rate [66,67], probably because of a faster viral replication rate process and/or stronger triggered cellular responses. To understand the peculiar pathogenic potential of RV-C serotypes, it is important to consider that CDHR3 (Cadherin-Related Family Member 3) has recently been recognized as a unique receptor for RV-C [29]. This gene was recently discovered as a susceptibility gene for asthma in early childhood. The product of its expression may act as a possible receptor for RV-C, explaining why, in genetically predisposed infants, RV bronchiolitis may trigger asthma and wheezing whereas bronchiolitis caused by other viruses may not. In infants younger than six months, the receptor 
CDHR3 is more highly expressed than in older infants. Furthermore, RV-C infects epithelial cells of the airways and triggers a consistent production of cytokines, such as IL-25 and IL-33, which activates a strong Th2 immune response.

Another locus geni (17q21) was recently discovered and linked to the development of wheezing as well as to the predisposition of asthmatic disease during the first months of life. Wheezing episodes during early-age stages seem indeed to be a stronger risk factor for asthma onset in children if 17q21 risk variants are present and this association is stronger for RV as compared to RSV infection $[29,68]$. Moreover, Pech et al. reported that RV infection may cause differential DNA methylation and subsequently differential mRNA expression in the epithelial cells of the affected airways. The same kind of DNA methylation modifications have been observed in many genes involved in anti-viral immune responses and in the pathogenesis of asthma [69].

A recent study [70] identifies six distinct patterns of cytokine production in response to RV infection, with major differences among patients that developed asthma, allergic sensitization, and lower RTIs during childhood. The risk of severe asthma is related to immune response, with the lowest interferon induction and the highest proinflammatory cytokine secretion. These results confirm the hypothesis that early-life sensitization against RV may lead to an increased risk of early onset asthma and recurrent wheezing. Therefore, the identification of these immunological profiles might be useful to understand in more detail the pathogenetic disease mechanisms, and subsequently to develop personalized approaches to therapy. A very recent study [71] identifies six clusters of nasal microbiota and hypothesizes about the influence of nasal microbiota during RV infection on virus load, host innate immune response, and clinical course. Some authors observed that RV did not play a major role in modifying the upper respiratory tract microbiota, although a direct correlation between rhinorrhea's severity and increased alpha-diversity after infection is described. This correlation could be explained by a variation in the microbiota caused by increased rhinorrea. Moreover, some studies have demonstrated that RV infection is associated with the detection of concomitant pathogenic bacteria in the patient's airways [72,73]. In particular, RV-A and RV-C infection may be characterized by a higher isolation in nasopharyngeal aspirates of Haemophilus Influenzae and Moraexella Catharralis, which are very common etiologic causes of acute respiratory infections [74]. These data confirm the metabolomic analysis comparing the nasopharingeal aspirate of infants during RV or RSV infection [75]. While, for the first case studies, the literature describes a relative abundance of $H$. Influenzae in the nasal aspirate, in the second situation, on the other hand, a higher presence of S. Pneumoniae was most frequently found.

These results offer novel findings and additional evidence for an in-depth analysis of the complex interaction between the microbial (virus and bacteria) features and the host's immunologic system in the pathobiology of bronchiolitis, a notoriously heterogeneous clinical disease.

\section{Antiviral Agents}

To date, no antiviral treatment for RV infection has been approved. The large number of RV serotypes and their considerable genetic diversity represented for years a major obstacle to the development of antiviral agents. Moreover, the RNA polymerase of this virus is reported to be error-prone, which leads to frequent natural mutations and an increased risk of drug resistance. Finally, to be effective, antiviral agents need to be administered during the early stages of respiratory infection and, in this sense, the lack of an accurate rapid diagnostic test represents a significant obstacle in RV treatment [76]. Additionally, the high cost of developing drugs has limited the interest of pharmaceutical companies to work in this area. However, some antivirals have exhibited inhibitory activity against RV.

Capsid binders are one of the main groups of RV antiviral agents. These drugs work through insertion into the VP1 hydrophobic pocket underneath the floor of the canyon, a depression of the viral capsid surface involved in cell receptor binding. This process prevents the capsid conformation changes that are necessary for RV to access the host cell. Pirodavir was the first capsid binder demonstrated 
to be capable of preventing RV infection in a human challenge model. However, this drug was demonstrated to be active only if administered within 10 minutes after RV challenge, while no antiviral effects was observed if administered $24 \mathrm{~h}$ after RV challenge [77]. Another capsid binding agent is Pleconaril, which is the first antiviral against RV tested in clinical trials. In two parallel prospective, double-blinded, placebo-controlled studies [78], the administration of this drug within the first $24 \mathrm{~h}$ after illness onset was able to consistently reduce the duration of symptoms in comparison with the placebo group. Nevertheless, the clinical benefits showed a strong correlation with the infecting virus's susceptibility to the drug [79]. One more capsid binder, Vapendavir, has been recently assessed in Phase II clinical trials, but its efficacy is still unclear [80]. The new discovery of RV-C type viruses, which have been proven to be lacking the accessible hydrophobic pocket, partially explains the limited efficacy of these drugs in intervention trials.

Another potential antiviral drug group against RV is protease inhibitors. These molecules act by preventing the cleavage of viral proteins, a crucial process required for an effective replication of RV into the infected host cell. One example is Rupintrivir, an inhibitor of the human RV 3C protease. This drug showed moderate in vitro antiviral activity against a range of different RV serotypes [81], including human RV C strains [82]. However, further in vivo trials are still required to test the actual efficacy of this and the other protease-inhibitors agents against RV.

A different strategy in preventing RV infection is the restriction of an RV bond to one of the three main host cell surface receptors (LDL-R, ICAM-1, or CDHR3). To date, only monoclonal antibodies specific for ICAM-1 have been tested. Even though these molecules have been demonstrated to have inhibiting potential towards RV replication in vitro, they showed limited in vivo efficacy in clinical trials in addition to a high cost [83]. Further and more detailed studies analyzing RV's infection and replication cycle are needed in the coming years to find new effective treatments against this very common but potentially dangerous micro-organism.

\section{Vaccines}

For decades, the development of vaccines against RV was considered unrealizable. Theoretically, an efficient and highly specific neutralizing humoral response against RV infection should confer solid protection. Nevertheless, because of the high and rising number of newly recognized viral strains, little cross-reactivity can be elicited by neutralizing antibodies [84].

In the last few decades, two main strategies have been implemented to overcome the high antigenic diversity of RV types to induce a valid protective immunity against different strains [85].

The first strategy is the development of a polyvalent vaccine comprising multiple RV serotypes. A previous attempt with a formalin-inactivated decavalent whole virus vaccine showed a significant increase in neutralizing antibody levels, active against up to $40 \%$ of known serotypes [86]. As a huge number of distinct RV strains circulate simultaneously $[87,88]$, a consistent number of virus antigenic molecules of various types should be contained in a polyvalent vaccine. Recently, a 50-valent inactivated $R V$ vaccine, assembled with an alhydrogel adjuvant, was demonstrated to be immunogenic against approximately one-third of the circulating RV types in rhesus macaques, inducing broadly neutralizing responses [89]. Of note, a limitation of the study conducted by Lee and colleagues is that the authors did not include RV-C antigens, which represents a crucial problem for pediatric populations. Those new multivalent $R V$ vaccine approaches now need to be tested in humans.

A second strategy to induce protective immunity against different RV serotypes is to develop subunit vaccines that consist of small but conserved regions of the RV molecular structure and connect it with an adjuvant able to enhance the T-cell response. The aim of this process is to increase the serological spectrum of RV coverage while limiting the number of necessary antigens. The VP1 and VP4 + VP2 (VP0) capsid regions are the most conserved viral capsid structures and provide promising vaccine targets [84]. In a mouse model, a recombinant RV16 VP0 vaccine in conjunction with a combination of incomplete Freund's (IFA) and CpG adjuvants elicited a strong cross-reactive Th1 response within the strain [89]. 
Overall, the recent findings in molecular virology, our understanding of RV's structure, and the identification of type-specific differences have led to a renewed interest in the development of vaccines against $R V$. The identification of highly conserved $R V$ regions and the design of an adjuvant polyvalent RV vaccine increase our hopes for future anti-RV vaccine development and efficient "weapons" against the variety of RV-associated diseases, including the increased risk for recurrent wheezing and subsequent childhood asthma. In addition, the use of biologic response modifiers to enhance the host's innate immune responses to RV has been recently investigated. A randomized placebo-controlled trial was conducted to test the hypothesis that the administration of inhaled IFN- $\beta$ might attenuate asthma exacerbations caused by RV and other respiratory viruses in patients with asthma after the onset of common cold symptoms [90]. Although the trial did not show a significant beneficial effect on asthmatic symptoms in the whole enrolled population, IFN- $\beta$ was demonstrated to have a positive effect on morning lung function (peak expiratory flow), and it was able to boost innate immunity response to respiratory viruses, both locally in the respiratory system and in the whole organism systemically and in the lungs. The primary hypothesis was that the administration of IFN- $\beta$ by inhalation could might be able to enhance innate immunity, thereby compensating for the known IFN- $\beta$ relative deficiency, which was previously demonstrated ex vivo in the epithelium of patients with moderate-severe asthma. Along this line, IFN- $\beta$ may have a convenient and favorable impact on virus-induced asthmatic exacerbations in difficult-to-treat patients, in whom the underlying disease is likely to be more severe with a higher risk of health impact [91]. The results of this trial suggest that IFN- $\beta$ may represent a potential effective treatment for virus-induced deteriorations of asthma in difficult-to-treat people with asthma and justify further future clinical studies conducted in this high-risk population.

\section{Conclusions}

$\mathrm{RV}$ is a very common pathogen that causes upper and lower RTI in children and adults. In the last few decades, it was observed to be related to subsequent development of asthma and recurrent wheezing in childhood, as widely demonstrated by several epidemiological studies. Indeed, the immune response of the host against viral infection in the first months of life is primarily Th2-mediated, and this response may lead to bronchial hyper-responsiveness in predisposed patients. In this context, a rising number of studies report a predominant Th2 polarization of host response to RV-infection-associated bronchiolitis as compared to RSV or other etiological viral agents. The broad variety of RV genotypes and the poor cross-protection from previous exposure to heterologous infections represent a major obstacle to the development of specific antiviral agents and vaccines against RV. Ongoing research on RV's structure, serotype-based peculiarities, and host factors that predispose to an asthmatic response may be useful to improve preventive and effective treatment strategies to limit the overall burden of RV disease, and the consequent risk of developing chronic respiratory morbidity in childhood.

Author Contributions: S.V. and M.L. contributed to the manuscript's concept. S.V., C.B., and M.F. contributed to the update of the literature review and to the writing and drafting of the article. M.L. revised the entire manuscript. All authors read and approved the final manuscript.

Funding: This research received no external funding.

Conflicts of Interest: The authors declare no conflicts of interest.

\section{References}

1. Gern, J.E. The ABCs of rhinoviruses, wheezing, and asthma. J. Virol. 2010, 84, 7418-7426. [CrossRef] [PubMed]

2. Atmar, R.L. Uncommon(ly considered) manifestations of infection with rhinovirus, agent of the common cold. Clin. Infect. Dis. 2005, 41, 266-267. [CrossRef]

3. Schilder, A.G.; Chonmaitree, T.; Cripps, A.W.; Rosenfeld, R.M.; Casselbrant, M.L.; Haggard, M.P.; Venekamp, R.P. Otitis media. Nat. Rev. Dis. Prim. 2016, 2, 16063. [CrossRef] 
4. Meissner, H.C. Viral bronchiolitis in children. N. Engl. J. Med. 2016, 374, 62-72. [CrossRef]

5. Jain, S.; Self, W.H.; Wunderink, R.G.; Fakhran, S.; Balk, R.; Bramley, A.M.; Reed, C.; Grijalva, C.G.; Anderson, E.J.; Courtney, D.M.; et al. Community-acquired pneumonia requiring hospitalization among U.S. adults. N. Engl. J. Med. 2015, 373, 415-427. [CrossRef] [PubMed]

6. Jain, S.; Williams, D.J.; Arnold, S.R.; Ampofo, K.; Bramley, A.M.; Reed, C.; Stockmann, C.; Anderson, E.J.; Grijalva, C.J.; Self, W.H.; et al. Community-acquired pneumonia requiring hospitalization among U.S. children. N. Engl. J. Med. 2015, 372, 835-845. [CrossRef]

7. Lau, S.K.; Yip, C.C.; Lin, A.W.; Lee, R.A.; So, L.Y.; Lau, Y.L.; Chan, K.H.; Woo, P.C.; Yuen, K.Y. Clinical and molecular epidemiology of human rhinovirus $C$ in children and adults in Hong Kong reveals a possible distinct human rhinovirus C subgroup. J. Infect. Dis. 2009, 200, 1096-1103. [CrossRef] [PubMed]

8. Reese, S.M.; Thompson, M.; Price, C.S.; Young, H.L. Evidence of nosocomial transmission of human rhinovirus in a neonatal intensive care unit. Am. J. Infect. Control. 2016, 44, 355-357. [CrossRef]

9. Savolainen-Kopra, C.; Korpela, T.; Simonen-Tikka, M.L.; Amiryousefi, A.; Ziegler, T.; Roivainen, M.; Hovi, T. Single treatment with ethanol hand rub is ineffective against human rhinovirus hand washing with soap and water removes the virus efficiently. J. Med. Virol. 2012, 543-547. [CrossRef]

10. Esposito, S.; Daleno, C.; Tagliabue, C.; Scala, A.; Tenconi, R.; Borzani, I.; Fossali, E.; Pelucchi, C.; Piralla, A.; Principi, N. Impact of rhinoviruses on pediatric community-acquired pneumonia. Eur. J. Clin. Microbiol. Infect. Dis. 2012, 31, 1637-1645. [CrossRef]

11. Heymann, P.W.; Platts-Mills, T.A.; Johnston, S.L. Role of viral infections, atopy and antiviral immunity in the etiology of wheezing exacerbations among children and young adults. Pediatr. Infect. Dis. J. 2005, 24, S217-S222. [CrossRef]

12. Singleton, R.J.; Bulkow, L.R.; Miernyk, K.; DeByle, C.; Pruitt, L.; Hummel, K.B.; Bruden, D.; Englund, J.A.; Anderson, L.J.; Lucher, L.; et al. Viral respiratory infections in hospitalized and community control children in Alaska. J. Med. Virol. 2010, 82, 1282-1290. [CrossRef]

13. Calvo, C.; Casas, I.; Garcia-Garcia, M.L.; Pozo, F.; Reyes, N.; Cruz, N.; García-Cuenllas, L.; Pérez-Breña, P. Role of rhinovirus $C$ respiratory infections in sick and healthy children in Spain. Pediatr. Infect. Dis. J. 2010, 29, 717-720. [CrossRef]

14. Jartti, T.; Lehtinen, P.; Vuorinen, T.; Koskenvuo, M.; Ruuskanen, O. Persistence of rhinovirus and enterovirus RNA after acute respiratory illness in children. J. Med. Virol. 2004, 72, 695-699. [CrossRef]

15. Turunen, R.; Koistinen, A.; Vuorinen, T.; Arku, B.; Söderlund-Venermo, M.; Ruuskanen, O.; Jartti, T. The first wheezing episode: Respiratory virus etiology, atopic characteristics, and illness severity. Pediatr. Allergy Immunol. 2014, 796-803. [CrossRef]

16. Kotaniemi-Syrjänen, A.; Reijonen, T.M.; Korhonen, K.; Waris, M.; Vainionpää, R.; Korppi, M. Wheezing due to rhinovirus infection in infancy: Bronchial hyperresponsiveness at school age. Pediatr. Int. 2008, 50, 506-510. [CrossRef]

17. Jartti, T.; Gern, J.E. Role of viral infections in the development and exacerbation of asthma in children. J. Allergy Clin. Immunol. 2017, 140, 895-906. [CrossRef]

18. Liu, L.; Pan, Y.; Zhu, Y.; Song, Y.; Su, X.; Yang, L.; Li, M. Association between rhinovirus wheezing illness and the development of childhood asthma: A metaanalysis. BMJ Open 2017, 7, e013034. [CrossRef]

19. Lo, D.; Kennedy, J.L.; Kurten, R.C.; Panettieri, R.A., Jr.; Koziol-White, C.J. Modulation of airway hyperresponsiveness by rhinovirus exposure. Respir. Res. 2018, 19, 208. [CrossRef]

20. Drysdale, S.B.; Mejias, A.; Ramilo, O. Rhinovirus-Not just the common cold. J. Infect. 2017, 74, S41-S46. [CrossRef]

21. Jartti, T.; Lehtinen, P.; Vuorinen, T.; Ruuskanen, O. Bronchiolitis: Age and previous wheezing episodes are linked to viral etiology and atopic characteristics. Pediatr. Infect. Dis. J. 2009, 28, 311-317. [CrossRef]

22. Self, W.H.; Williams, D.J.; Zhu, Y.; Ampofo, K.; Pavia, A.T.; Chappell, J.D.; Hymas, W.C.; Stockmann, C.; Bramley, A.M.; Schneider, E.; et al. Respiratory viral detection in children and adults: Comparing asymptomatic controls and patients with community-acquired pneumonia. J. Infect. Dis. 2016, 213, 584-591. [CrossRef]

23. Takeyama, A.; Hashimoto, K.; Sato, M.; Sato, T.; Tomita, Y.; Maeda, R.; Ito, M.; Katayose, M.; Kawasaki, Y.; Hosoya, M. Clinical and epidemiologic factors related to subsequent wheezing after virus-induced lower respiratory tract infections in hospitalized pediatric patients younger than 3 years. Eur. J. Pediatr. 2014, 173, 959-966. [CrossRef] 
24. Hyvarinen, M.K.; Kotaniemi-Syrjanen, A.; Reijonen, T.M.; Korhonen, K.; Korppi, M.O. Teenage asthma after severe early childhood wheezing: An 11-year prospective follow-up. Pediatr. Pulmonol. 2005, 40, 316-323. [CrossRef]

25. Jackson, D.J.; Gangnon, R.E.; Evans, M.D.; Roberg, K.A.; Anderson, E.L.; Pappas, T.E.; Printz, M.C.; Lee, W.M.; Shult, P.A.; Reisdorf, E.; et al. Wheezing rhinovirus illnesses in early life predict asthma development in high-risk children. Am. J. Respir. Crit. Care Med. 2008, 178, 667-672. [CrossRef]

26. Midulla, F.; Nicolai, A.; Ferrara, M.; Gentile, F.; Pierangeli, A.; Bonci, E.; Scagnolari, C.; Moretti, C.; Antonelli, G.; Papoff, P. Recurrent wheezing 36 months after bronchiolitis is associated with rhinovirus infections and blood eosinophilia. Acta Paediatr. 2014, 103, 1094-1099. [CrossRef]

27. De Winter, J.J.; Bont, L.; Wilbrink, B.; van der Ent, C.K.; Smit, H.A.; Houben, M.L. Rhinovirus wheezing illness in infancy is associated with medically attended third year wheezing in low risk infants: Results of a healthy birth cohort study. Immun. Inflamm. Dis. 2015, 3, 398-405. [CrossRef]

28. Kusel, M.M.; de Klerk, N.H.; Holt, P.G.; Kebadze, T.; Johnston, S.L.; Sly, P.D. Role of respiratory viruses in acute upper and lower respiratory tract illness in the first year of life: A birth cohort study. Pediatr. Infect. Dis. J. 2006, 25, 680-686. [CrossRef]

29. Jartti, T.; Smits, H.H.; Bønnelykke, K.; Bircan, O.; Elenius, V.; Konradsen, J.R.; Maggina, P.; Makrinioti, H.; Stokholm, J.; Hedlin, G.; et al. EAACI task force on clinical practice recommendations on preschool wheeze. bronchiolitis needs a revisit: Distinguishing between virus entities and their treatments. Allergy 2019, 74, 40-52. [CrossRef]

30. Dumas, O.; Hasegawa, K.; Mansbach, J.M.; Sullivan, A.F.; Piedra, P.A.; Camargo, C.A., Jr. Severe bronchiolitis profiles and risk of recurrent wheeze by age 3 years. J. Allergy Clin. Immunol. 2019, 143, 1371-1379. [CrossRef]

31. International Committee on Taxonomy of Viruses. Available online: https:/talk.ictvonline.org/taxonomy/ (accessed on 27 March 2019).

32. Palmenberg, A.C.; Spiro, D.; Kuzmickas, R.; Wang, S.; Djikeng, A.; Rathe, J.A.; Fraser-Liggett, C.M.; Liggett, S.B. Sequencing and analyses of all known human rhinovirus genomes reveal structure and evolution. Science 2009, 324, 55-59. [CrossRef]

33. To, K.K.W.; Yip, C.C.Y.; Yuen, K.Y. Rhinovirus-From bench to bedside. J. Formos. Med. Assoc. 2017, 116, 496-504. [CrossRef]

34. Royston, L.; Tapparel, C. Rhinoviruses and respiratory enteroviruses: Not as simple as ABC. Viruses 2016, 8, 16. [CrossRef]

35. L'Huillier, A.G.; Tapparel, C.; Turin, L.; Boquete-Suter, P.; Thomas, Y.; Kaiser, L. Survival of rhinoviruses on human fingers. Clin. Microbiol. Infect. 2015, 21, 381-385. [CrossRef]

36. Ahn, J.G.; Kim, D.S.; Kim, K.H. Clinical characteristics and cytokine profiles of children with acute lower respiratory tract infections caused by human rhinovirus. PLOS ONE 2018, 13, e0198624. [CrossRef]

37. Winther, B.; Gwaltney, J.M.; Hendley, J.O. Respiratory virus infection of monolayer cultures of human nasal epithelial cells. Am. Rev. Respir. Dis. 1990, 141, 839-845. [CrossRef]

38. Unger, B.L.; Ganesan, S.; Comstock, A.T.; Faris, A.N.; Hershenson, M.B.; Sajjan, U.S. Nod-like receptor X-1 is required for rhinovirus-induced barrier dysfunction in airway epithelial cells. J. Virol. 2014, 88, 3705-3718. [CrossRef]

39. Jacobs, S.E.; Lamson, D.M.; St George, K.; Walsh, T.J. Human rhinoviruses. Clin. Microbiol. Rev. 2013, 26, 135-162. [CrossRef]

40. Ritchie, A.I.; Jackson, D.J.; Edwards, M.R.; Johnston, S.L. Airway epithelial orchestration of innate immune function in response to virus infection. A focus on asthma. Ann. Am. Thorac. Soc. 2016, 13, S55-S63.

41. Fensterl, V.; Sen, G.C. Interferons and viral infections. Biofactors 2009, 35, 14-20. [CrossRef]

42. Biron, C.A. Initial and innate responses to viral infections-Pattern setting in immunity or disease. Curr. Opin. Microbiol. 1999, 2, 374-381. [CrossRef]

43. Fraenkel, D.J.; Bardin, P.G.; Sanderson, G.; Lampe, F.; Johnston, S.L.; Holgate, S.T. Lower airways inflammation during rhinovirus colds in normal and in asthmatic subjects. Am. J. Respir. Crit. Care Med. 1995, 151, 879-886.

44. Makris, S.; Johnston, S. Recent advances in understanding rhinovirus immunity. F1000Research $2018,7$. [CrossRef]

45. Miller, E.K.; Hernandez, J.Z.; Wimmenauer, V.; Shepherd, B.E.; Hijano, D.; Libster, R.; Serra, M.E.; Bhat, N.; Batalle, J.P.; Mohamed, Y.; et al. A mechanistic role for type III IFN- $\lambda 1$ in asthma exacerbations mediated by human rhinoviruses. Am. J. Respir. Crit. Care Med. 2012, 185, 508-516. [CrossRef] 
46. Jones, A.C.; Anderson, D.; Galbraith, S.; Fantino, E.; Gutierrez Cardenas, D.; Read, J.F.; Serralha, M.; Holt, B.J.; Strickland, D.H.; Sly, P.D.; et al. Personalised transcriptomics reveals heterogeneous immunophenotypes in children with viral bronchiolitis. Am. J. Respir. Crit. Care Med. 2018. [CrossRef]

47. Khoo, S.K.; Read, J.; Franks, K.; Zhang, G.; Bizzintino, J.; Coleman, L.; McCrae, C.; Öberg, L.; Troy, N.M.; Prastanti, F.; et al. Upper airway cell transcriptomics identify a major new immunological phenotype with strong clinical correlates in young children with acute wheezing. J. Immunol. 2019, 202, 1845-1858. [CrossRef]

48. Turi, K.N.; Shankar, J.; Anderson, L.J.; Rajan, D.; Gaston, K.; Gebretsadik, T.; Das, S.R.; Stone, C.; Larkin, E.K.; Rosas-Salazar, C.; et al. Infant viral respiratory infection nasal immune-response patterns and their association with subsequent childhood recurrent wheeze. Am. J. Respir. Crit. Care Med. 2018, 198, 1064-1073. [CrossRef]

49. Stenberg Hammar, K.; Niespodziana, K.; van Hage, M.; Kere, J.; Valenta, R.; Hedlin, G.; Söderhäll, C. Reduced CDHR3 expression in children wheezing with rhinovirus. Pediatr. Allergy Immunol. 2018, 29, $200-206$. [CrossRef]

50. Fedele, G.; Schiavoni, I.; Nenna, R.; Pierangeli, A.; Frassanito, A.; Leone, P.; Petrarca, L.; Scagnolari, C.; Midulla, F. Analysis of the immune response in infants hospitalized with viral bronchiolitis shows different Th1/Th2 profiles associated with respiratory syncytial virus and human rhinovirus. Pediatr. Allergy Immunol. 2018, 29, 555-557. [CrossRef]

51. Jackson, D.J.; Makrinioti, H.; Rana, B.M.; Shamji, B.W.; Trujillo-Torralbo, M.B.; Footitt, J.; Del-Rosario, J.; Telcian, A.G.; Nikonova, A.; Zhu, J.; et al. IL-33-dependent type 2 inflammation during rhinovirus-induced asthma exacerbations in vivo. Am. J. Respir. Crit. Care Med. 2014, 190, 1373-1382. [CrossRef]

52. Beale, J.; Jayaraman, A.; Jackson, D.J.; Macintyre, J.D.R.; Edwards, M.R.; Walton, R.P.; Zhu, J.; Man Ching, Y.; Shamji, B.; Edwards, M.; et al. Rhinovirus-induced IL-25 in asthma exacerbation drives type 2 immunity and allergic pulmonary inflammation. Sci. Transl. Med. 2014, 6. [CrossRef]

53. Sajjan, U.; Wang, Q.; Zhao, Y.; Gruenert, D.C.; Hershenson, M.B. Rhinovirus disrupts the barrier function of polarized airway epithelial cells. Am. J. Respir. Crit. Care Med. 2008, 178, 1271-1281. [CrossRef]

54. Shariff, S.; Shelfoon, C.; Holden, N.S.; Traves, S.L.; Wiehler, S.; Kooi, C.; Proud, D.; Leigh, R. Human rhinovirus infection of epithelial cells modulates airway smooth muscle migration. Am. J. Respir. Cell Mol. Biol. 2017, 56, 796-803. [CrossRef]

55. Leigh, R.; Oyelusi, W.; Wiehler, S.; Koetzler, R.; Zaheer, R.S.; Newton, R.; Proud, D. Human rhinovirus infection enhances airway epithelial cell production of growth factors involved in airway remodeling. J. Allergy Clin. Immunol. 2008, 121, 1238-1245. [CrossRef]

56. Hong, J.Y.; Bentley, J.K.; Chung, Y.; Lei, J.; Steenrod, J.M.; Chen, Q.; Sajjan, U.S.; Hershenson, M.B. Neonatal rhinovirus induces mucous metaplasia and airways hyperresponsiveness through IL-25 and type 2 innate lymphoid cells. J. Allergy Clin. Immunol. 2014, 134, 429-439. [CrossRef]

57. Restori, K.H.; Srinivasa, B.T.; Ward, B.J.; Fixman, E.D. Neonatal immunity, respiratory virus infections, and the development of asthma. Front. Immunol. 2018, 9, 1249. [CrossRef]

58. Kollmann, T.R.; Kampmann, B.; Mazmanian, S.K.; Marchant, A.; Levy, O. Protecting the newborn and young infant from infectious diseases: Lessons from immune ontogeny. Immunity 2017, 46, 350-363. [CrossRef]

59. Holt, P.G.; Mok, D.; Panda, D.; Renn, L.; Fabozzi, G.; deKlerk, N.H.; Kusel, M.M.H.; Serralha, M.; Hollams, E.M.; Holt, B.J.; et al. Developmental regulation of type 1 and type 3 interferon production and risk for infant infections and asthma development. J. Allergy Clin. Immunol. 2019, 143, 1176-1182. [CrossRef]

60. Bartlett, N.W.; Singanayagam, A.; Johnston, S.L. Mouse models of rhinovirus infection and airways disease. Methods Mol Biol. 2015, 1221, 181-188.

61. Schneider, D.; Hong, J.Y.; Bowman, E.R.; Chung, Y.; Nagarkar, D.R.; McHenry, C.L.; Goldsmith, A.M.; Bentley, J.K.; Lewis, T.C.; Hershenson, M.B. Macrophage/epithelial cell CCL2 contributes to rhinovirus-induced hyperresponsiveness and inflammation in a mouse model of allergic airways disease. Am. J. Physiol.-Lung Cell Mol. Physiol. 2013, 304, L162-L169. [CrossRef]

62. Hasegawa, K.; Hoptay, C.E.; Harmon, B.; Celedón, J.C.; Mansbach, J.M.; Piedra, P.A.; Freishtat, R.J.; Camargo, C.A., Jr. Association of type 2 cytokines in severe rhinovirus bronchiolitis during infancy with risk of developing asthma: A multicenter prospective study. Allergy 2019. [CrossRef]

63. Rossi, G.A.; Colin, A.A. Infantile respiratory syncytial virus and human rhinovirus infections: Respective role in inception and persistence of wheezing. Eur. Respir. J. 2015, 45, 774-789. [CrossRef] 
64. Caballero, M.T.; Hijano, D.R.; Acosta, P.L.; Mateu, C.G.; Marcone, D.N.; Linder, J.E.; Talarico, L.B.; Elder, J.M.; Echavarria, M.; Miller, E.K.; et al. INFANT Respiratory Network. Interleukin-13 associates with life-threatening rhinovirus infections in infants and young children. Pediatr. Pulmonol. 2018, 53, 787-795. [CrossRef]

65. Lambkin-Williams, R.; Noulin, N.; Mann, A.; Catchpole, A.; Gilbert, A.S. The human viral challenge model: Accelerating the evaluation of respiratory antivirals, vaccines and novel diagnostics. Respir. Res. 2018, 19, 123. [CrossRef]

66. Zheng, S.Y.; Wang, L.L.; Ren, L.; Luo, J.; Liao, W.; Liu, E.M. Epidemiological analysis and follow-up of human rhinovirus infection in children with asthma exacerbation. J. Med. Virol. 2018, 90, 219-228. [CrossRef]

67. Cox, D.W.; Bizzintino, J.; Ferrari, G.; Khoo, S.K.; Zhang, G.; Whelan, S.; Lee, W.M.; Bochkov, Y.A.; Geelhoed, G.C.; Goldblatt, J.; et al. Human rhinovirus species C infection in young children with acute wheeze is associated with increased acute respiratory hospital admissions. Am. J. Respir. Crit. Care Med. 2013, 188, 1358-1364. [CrossRef]

68. Calışkan, M.; Bochkov, Y.A.; Kreiner-Møller, E.; Bønnelykke, K.; Stein, M.M.; Du, G.; Bisgaard, H.; Jackson, D.J.; Gern, J.E.; Lemanske, R.F., Jr.; et al. Rhinoviruswheezing illness and genetic risk of childhood-onset asthma. N. Engl. J. Med. 2013, 368, 1398-1407. [CrossRef]

69. Pech, M.; Weckmann, M.; König, I.R.; Franke, A.; Heinsen, F.A.; Oliver, B.; Ricklefs, I.; Fuchs, O.; Rabe, K.; Hansen, G.; et al. ALLIANCE-study group. Rhinovirus infections change DNA methylation and mRNA expression in children with asthma. PLoS ONE. 2018, 13, e0205275. [CrossRef]

70. Custovic, A.; Belgrave, D.; Lin, L.; Bakhsoliani, E.; Telcian, A.G.; Solari, R.; Murray, C.S.; Walton, R.P.; Curtin, J.; Edwards, M.R.; et al. Cytokine responses to rhinovirus and development of asthma, allergic sensitization, and respiratory infections during childhood. Am. J. Respir. Crit. Care Med. 2018, 197, 1265-1274. [CrossRef]

71. Lehtinen, M.J.; Hibberd, A.A.; Männikkö, S.; Yeung, N.; Kauko, T.; Forssten, S.; Lehtoranta, L.; Lahtinen, S.J.; Stahl, B.; Lyra, A.; et al. Nasal microbiota clusters associate with inflammatory response, viral load, and symptom severity in experimental rhinovirus challenge. Sci. Rep. 2018, 8, 11411. [CrossRef]

72. Karppinen, S.; Teräsjärvi, J.; Auranen, K.; Schuez-Havupalo, L.; Siira, L.; He, Q.; Waris, M.; Peltola, V. Acquisition and transmission of streptococcus pneumoniae are facilitated during rhinovirus infection in families with children. Am. J. Respir. Crit. Care Med. 2017, 196, 1172-1180. [CrossRef]

73. Kloepfer, K.M.; Lee, W.M.; Pappas, T.E.; Kang, T.J.; Vrtis, R.F.; Evans, M.D.; Gangnon, R.E.; Bochkov, Y.A.; Jackson, D.J.; Lemanske, R.F.; et al. Detection of pathogenic bacteria during rhinovirus infection is associated with increased respiratory symptoms and asthma exacerbations. J. Allergy Clin. Immunol. 2014, 133. [CrossRef]

74. Bashir, H.; Grindle, K.; Vrtis, R.; Vang, F.; Kang, T.; Salazar, L.; Anderson, E.; Pappas, T.; Gangnon, R.; Evans, M.D.; et al. Association of rhinovirus species with common cold and asthma symptoms and bacterial pathogens. J. Allergy Clin. Immunol. 2018, 141, 822-824.e9. [CrossRef]

75. Stewart, C.J.; Hasegawa, K.; Wong, M.C.; Ajami, N.J.; Petrosino, J.F.; Piedra, P.A.; Espinola, J.A.; Tierney, C.N.; Camargo, C.A., Jr.; Mansbach, J.M. Respiratory syncytial virus and rhinovirus bronchiolitis are associated with distinct metabolic pathways. J. Infect. Dis. 2018, 217, 1160-1169. [CrossRef]

76. Basnet, S.; Palmenberg, A.C.; Gern, J.E. Rhinoviruses and Their Receptors. Chest 2019, 155, $1018-1025$. [CrossRef]

77. Hayden, F.G.; Hipskind, G.J.; Woerner, D.H.; Eisen, G.F.; Janssens, M.; Janssen, P.A.; Andries, K. Intranasal pirodavir (R77,975) treatment of rhinovirus colds. Antimicrob. Agents Chemother. 1995, 39, 290-294. [CrossRef]

78. Hayden, F.G.; Herrington, D.T.; Coats, T.L.; Kim, K.; Cooper, E.C.; Villano, S.A.; Liu, S.; Hudson, S.; Pevear, D.C.; Collett, M.; et al. Efficacy and safety of oral pleconaril for treatment of colds due to picornaviruses in adults: Results of 2 double-blind, randomized, placebo-controlled trials. Clin. Infect. Dis. 2003, 36, 1523-1532. [CrossRef]

79. Pevear, D.C.; Hayden, F.G.; Demenczuk, T.M.; Barone, L.R.; McKinlay, M.A.; Collett, M.S. Relationship of pleconaril susceptibility and clinical outcomes in treatment of common colds caused by rhinoviruses. Antimicrob. Agents Chemother. 2005, 49, 4492-4499. [CrossRef]

80. Mirabelli, C.; Scheers, E.; Neyts, J. Novel therapeutic approaches to simultaneously target rhinovirus infection and asthma/COPD pathogenesis. F1000Research 2017, 6, 1860. [CrossRef] 
81. Kawatkar, S.P.; Gagnon, M.; Hoesch, V.; Tiong-Yip, C.; Johnson, K.; Ek, M.; Nilsson, E.; Lister, T.; Olsson, L.; Patel, J. Design and structure-activity relationships of novel inhibitors of human rhinovirus $3 \mathrm{C}$ protease. Bioorg. Med. Chem. Lett. 2016, 26, 3248-3252. [CrossRef]

82. Mello, C.; Aguayo, E.; Rodriguez, M.; Lee, G.; Jordan, R.; Cihlar, T.; Birkus, G. Multiple classes of antiviral agents exhibit in vitro activity against human rhinovirus type C. Antimicrob. Agents Chemother. 2014, 58, 1546-1555. [CrossRef]

83. Glanville, N.; Johnston, S.L. Challenges in developing a cross-serotype rhinovirus vaccine. Curr. Opin. Virol. 2015, 11, 83-88. [CrossRef]

84. Stobart, C.C.; Nosek, J.M.; Moore, M.L. Rhinovirus biology, antigenic diversity, and advancements in the design of a human rhinovirus vaccine. Front. Microbiol. 2017, 8, 2412. [CrossRef]

85. Hamory, B.H.; Hamparian, V.V.; Conant, R.M.; Gwaltney, J.M., Jr. Human responses to two decavalent rhinovirus vaccines. J. Infect. Dis. 1975, 132, 623-629. [CrossRef]

86. Lee, W.M.; Kiesner, C.; Pappas, T.; Lee, I.; Grindle, K.; Jartti, T.; Jakiela, B.; Lemanske, R.F., Jr.; Shult, P.A.; Gern, J.E. A diverse group of previously unrecognized human rhinoviruses are common causes of respiratory illnesses in infants. PLoS ONE 2007, 2, e966. [CrossRef]

87. Martin, E.K.; Kuypers, J.; Chu, H.Y.; Lacombe, K.; Qin, X.; Strelitz, B.; Bradford, M.; Jones, C.; Klein, E.J.; Englund, J.A. Molecular epidemiology of human rhinovirus infections in the pediatric emergency department. J. Clin. Virol. 2015, 62, 25-31. [CrossRef]

88. Lee, S.; Nguyen, M.T.; Currier, M.G.; Jenkins, J.B.; Strobert, E.A.; Kajon, A.E.; Madan-Lala, R.; Bochkov, Y.A.; Gern, J.E.; Roy, K.; et al. A polyvalent inactivated rhinovirus vaccine is broadly immunogenic in rhesus macaques. Nat. Commun. 2016, 7, 12838. [CrossRef]

89. Glanville, N.; McLean, G.R.; Guy, B.; Lecouturier, V.; Berry, C.; Girerd, Y.; Gregoire, C.; Walton, R.P.; Pearson, R.M.; Kebadze, T. Cross-serotype immunity induced by immunization with a conserved rhinovirus capsid protein. PLoS Pathog. 2013, 9, e1003669. [CrossRef]

90. Djukanović, R.; Harrison, T.; Johnston, S.L.; Gabbay, F.; Wark, P.; Thomson, N.C.; Niven, R.; Singh, D.; Reddel, H.K.; Davies, D.E.; et al. INTERCIA Study Group. The effect of inhaled IFN- $\beta$ on worsening of asthma symptoms caused by viral infections. A randomized trial. Am. J. Respir. Crit. Care Med. 2014, 190, 145-154. [CrossRef]

91. Wark, P.A.; Johnston, S.L.; Bucchieri, F.; Powell, R.; Puddicombe, S.; LazaStanca, V.; Holgate, S.T.; Davies, D.E. Asthmatic bronchial epithelial cells have a deficient innate immune response to infection with rhinovirus. J. Exp. Med. 2005, 201, 937-947. [CrossRef]

(C) 2019 by the authors. Licensee MDPI, Basel, Switzerland. This article is an open access article distributed under the terms and conditions of the Creative Commons Attribution (CC BY) license (http://creativecommons.org/licenses/by/4.0/). 